\title{
DISCUSSIE
}

\section{Forensische psychologie, neurobiologie en preventie: kritische reflectie op nieuwe ontwikkelingen ${ }^{*}$}

\author{
Dorothee Horstkötter, Carla van El, Thomas Rinne, Guido de Wert \& Toine Pieters
}

De preventie van criminaliteit staat hoog op de maatschappelijke en politieke agenda. Naast een juridisch speelt hierbij ook een psychiatrisch kader een belangrijke rol. De laatste jaren gaat veel aandacht uit naar de neurofysiologie, neurobiologie en genetica. Sommigen hopen dat op inzichten uit deze vakgebieden gebaseerde detectie-, interventie- en beoordelingspraktijken beter en effectiever zouden zijn. Het is echter nodig om tijdig te reflecteren op de mogelijkheden en beperkingen van een dergelijke aanpak en ook op de ethische en maatschappelijke implicaties ervan. Dit artikel bespreekt implicaties van achtereenvolgens de vroege detectie van risicokinderen en preventie van antisociaal gedrag en beoordelingsprocedures pro Justitia van verdachten van een ernstig vergrijp.

\section{Inleiding}

De preventie van criminaliteit staat hoog op de maatschappelijke en politieke agenda. Er is veel aandacht voor jongeren die ernstige delicten plegen. Bij verdachten en daders van ernstige vergrijpen is de roep om de maatschappij tegen recidive te beschermen sterk. Naast een juridisch kader speelt bij de beoordeling van crimineel en antisociaal gedrag ook een psychiatrisch kader een belangrijke rol. Veel personen die met politie en justitie in aanraking komen, hebben psychische en gedragsstoornissen. Vaak worden vroege detectie van kinderen met een potentieel risico op gedragsstoornissen en interventie gericht op primaire preventie enerzijds (Farrington \& Coid, 2003; Farrington \& Welsh, 2007) en het optimaliseren van forensisch-psychiatrische beoordelingsprocedures van verdachten van ernstige vergrijpen anderzijds (Nordstrom e.a., 2011; Von Borries e.a., 2013) voorgesteld als belangrijke instrumenten van criminaliteitspreventie. Daarmee

* Dit artikel is gebaseerd op de resultaten van twee onderzoeksprojecten van het CSG Centre for Society and the Life Sciences, gefinancierd door het Netherlands Genomics Initiative. Dorothee Horstkötter en Guido de Wert waren betrokken bij 'The promise and pitfalls of the genomics of antisocial behaviour for prevention: a comparative ethical analysis'. Carla van El en Toine Pieters werkten aan 'Genes, brains and criminality in context: assessment of knowledge development in genomics and neurobiology and the transfer thereof into psychiatric forensic practice'. Zij werkten hiervoor samen met het NIFP Pieter Baan Centrum, waar Thomas Rinne aan verbonden is.

De bijdrage van Dorothee Horstkötter en Guido de Wert werd tevens gefinancierd door een subsidie van het ZonMw-programma 'Ethiek en Gezondheid' (nr. 731010007). 
worden vragen naar geschikte methoden voor dergelijke praktijken ook belangrijke vragen voor de criminologie. De laatste jaren wordt veel onderzoek gedaan naar de relatie tussen neurofysiologie, neurobiologie en genetica en gedragsstoornissen (Fishbein, 2000; Hodgins e.a., 2009; WODC, 2006). Hierbij ligt in toenemende mate de nadruk op de complexe interactie tussen biologische en omgevingsfactoren (Caspi \& Moffitt, 2006; Moffitt e.a., 2006). Sommigen hopen dat op neurowetenschappelijke en gedragsgenetische inzichten gebaseerde detectie-, interventie- en beoordelingspraktijken beter en effectiever zijn dan de huidige aanpak (Beauchaine e.a., 2008; De Kogel e.a., 2013; Egger e.a., 2005; Van Goozen \& Fairchild, 2008). Het is echter nodig om tijdig te reflecteren op de mogelijkheden en beperkingen van een dergelijke aanpak en ook op de ethische en maatschappelijke implicaties ervan (Horstkötter e.a., 2011; 2013; 2014a; Singh \& Rose, 2009).

In dit artikel bespreken wij twee terreinen van de forensische psychologie en psychiatrie waarop de wetenschappelijke ontwikkelingen van invloed kunnen zijn:

a vroege detectie van kinderen met een mogelijk risico op het ontwikkelen van gedragsproblemen en primaire preventie van antisociaal gedrag;

b beoordelingsprocedures pro Justitia van verdachten van een ernstig vergrijp.

\section{Biomedisch onderzoek en verwachtingen voor de praktijk}

Gedragsgenetisch onderzoek werd ooit aangewakkerd door de observatie dat crimineel gedrag zich vaak binnen dezelfde families voordoet. Erfelijkheidsstudies hebben echter laten zien dat hierbij meestal sprake is van een complex samenspel van omgevings- en genetische factoren (Viding e.a., 2008). Moleculair-genetische studies trachten gensequenties te identificeren die de regulatie van neurotransmitters, zoals serotonine of cortisol, beïnvloeden (Comings, 2000). Wat betreft mogelijke toepassingen is echter terughoudendheid geboden. Eventuele genetische testen hebben beperkte voorspellende waarde. Het 'agressie-gen' bestaat niet. Er is hoogstens sprake van een mogelijke genetische kwetsbaarheid (susceptibility) (Forzano e.a., 2010). Omgevingsfactoren, zoals voedselgebrek en verwaarlozing, ook bij vorige generaties, kunnen zogenoemde epigenetische veranderingen teweegbrengen, waarbij veranderingen in de expressie van genen worden vastgelegd. Sommigen hebben geopperd dat onderscheid gemaakt kan (en moet) worden tussen subtypen van agressie (bijvoorbeeld instrumentele versus reactieve agressie) en dat de ontwikkeling van preventie- en interventiepraktijken hierop afgestemd kan (en moet) worden (Viding e.a., 2009; 2012). Hersenscans trachten afwijkingen in hersenstructuren en functies te herkennen. Hierbij gaat het vooral om onderzoek naar hersengebieden die betrokken zijn bij de regulering van emoties, de verwerking van sociale informatie, doelgericht handelen en inhiberende gedragscontrole (Shirtcliff e.a., 2009; Sterzer \& Stadler, 2009). Wat betreft de neurofysiologie heeft men laten zien dat sommige kinderen met gedragsstoornissen en sommige daders van ernstige misdaden een lagere hartslag in rust en een lagere huidgeleiding hebben (Herpertz e.a., 2001; Ortiz \& Raine, 2004) dan leeftijdsgenoten en dat deze kenmerken in verband gebracht kunnen 
worden met een abnormale stressreactie en verminderde angstwaarneming (Popma e.a., 2006).

Signalering van en interventie bij kinderen met een mogelijk risico Wat betreft mogelijke toepassingen van deze bevindingen worden verschillende suggesties gedaan. Enerzijds wordt voorgesteld om kinderen met al bestaande gedragsproblemen interventies aan te bieden die op hun specifieke genetische, neurobiologische en/of neurofysiologische kenmerken zijn toegespitst (Beauchaine e.a., 2008; Frick \& Petitclerc, 2009; Shirtcliff e.a., 2009). Anderzijds worden psychofarmacologische interventies, transcraniële magnetische stimulatie (TMS) en neurofeedback (Van Goozen \& Fairchild, 2008) voorgesteld. In een behandelcontext veronderstellen dergelijke interventies neurobiologisch gefundeerde diagnostiek. Men hoopt deze ontwikkelingen op termijn ook te kunnen inzetten ter preventie door het identificeren van kinderen met een potentieel risico op gedragsstoornissen. Deze toepassingen zouden echter systematische signaleringspraktijken en mogelijk genetische en/of neurobiologische screening vergen (Van Goozen \& Fairchild, 2008). Immers, als men antisociaal gedrag wil voorkomen nog vóórdat jonge kinderen gedragsstoornissen (of afwijkingen) laten zien, zoals geregeld geopperd wordt (Tremblay \& Japel, 2003), zou men ook zich (nog) normaal gedragende kinderen hierbij moeten betrekken.

\section{Pro-Justitiabeoordelingen en risicoanalyses van verdachten}

Ook voor de forensische psychologie en psychiatrie en de rechtspraak bestaan verwachtingen ten aanzien van het gebruik van neurobiologische en genetische inzichten (Gurley \& Marcus, 2008; Nordstrom e.a., 2011). Met name als er sprake is van ernstig normoverschrijdend gedrag of geweld lijkt het zinvol om te bezien of een probleem in de hersenen een rol speelt. Momenteel kan de rechtbank of het Openbaar Ministerie bij ernstige vergrijpen een gedragsdeskundige rapportage pro Justitia aanvragen naar de persoon van de verdachte. Daarbij wordt niet alleen onderzocht of er sprake is van een gebrekkige ontwikkeling van iemands geestvermogens en/of van de aanwezigheid van een stoornis die mogelijk van invloed is geweest op het delict, maar ook of er kans op recidive bestaat. Ook kan een behandeladvies gegeven worden. In het Pieter Baan Centrum kan de rapporterend forensisch psychiater of psycholoog indien noodzakelijk een gedragsneuroloog inschakelen, aanvullend neuropsychologisch onderzoek laten verrichten of een MRI-scan laten maken om hersenorganiciteit vast te stellen (door bijvoorbeeld tumoren of posttraumatische cerebrale beschadiging of vaataandoeningen). Daarnaast vindt ook milieuonderzoek plaats, dat de bevindingen in een ontwikkelingsperspectief plaatst. In de bestaande beoordelingspraktijk zijn dus reeds elementen van het biopsychosociale model aanwezig dat door Engel al in 1977 (Engel, 1977) werd gepropageerd. Wellicht kunnen deze praktijken op termijn verder aangevuld worden met bijvoorbeeld meer verfijnde hersenscans, neuroendrocrinologisch of genetisch onderzoek. De combinatie van dergelijke diagnostische benaderingen met verdiepend neuropsychologisch onderzoek kan een zinvolle praktische vertaling bieden van de bevindingen van onderzoek naar neurobiologische processen (Von Borries e.a., 2013). Zo zou preciezere informatie over 
iemands reactie op stress, iemands impulsiviteit of de doorwerking van hersenschade verkregen kunnen worden. Dit zou tot een nauwkeurigere diagnose en behandeling kunnen leiden. Dat daar in Nederland interesse voor bestaat, blijkt bijvoorbeeld uit initiatieven van het WODC (De Kogel, 2008). Een vergelijkbare hoop op verbetering betreft ook de taxatie van het recidiverisico. De in de afgelopen jaren ontwikkelde instrumenten die informatie over beschermende en risicofactoren structureren, zijn weliswaar een relatieve verbetering indien zij samen met de klinische beoordeling van gedragsdeskundigen worden ingezet, maar, zoals De Vogel e.a. onlangs beargumenteerden, er zijn talrijke verbeterpunten nodig (De Vogel e.a., 2013), met name wat betreft de vertaling van groepsnormen naar geïndividualiseerde risicoprofielen.

\section{Kritische reflectie}

De ontwikkeling van biomedisch geïnformeerde methoden van vroege signalering, primaire preventie en beoordeling wordt vaak voorgesteld als een vooral interventietechnische kwestie. De vraag is daarbij vooral welke factoren een rol spelen en hoe deze kunnen worden gemeten, respectievelijk aangepakt. Vragen naar het waarom of waartoe en naar gepaste voorwaarden of mogelijke (onbedoelde) gevolgen worden echter nauwelijks gesteld.

\section{Vroege preventie: mogelijke valkuilen en belangenconflicten}

Biomedische benaderingen van gedrag dat geassocieerd kan worden met criminaliteit, zoals agressief en impulsief gedrag, werden van begin af aan begeleid door kritische commentaren wat betreft mogelijke ethische, sociale en juridische implicaties (Nuffield Council on Bioethics, 2002; Singh \& Rose, 2009; Wasserman \& Wachbroit, 2001). Natuurlijk zijn voor een adequate ethische beoordeling ook de mogelijke voordelen van belang. Voor zover als biomedisch geïnformeerde maatregelen beter in staat blijken kinderen en hun gezinnen te helpen en hun welzijn en toekomst te verbeteren, kunnen deze van grote waarde zijn. Hetzelfde geldt als het mogelijk blijkt op deze manier de maatschappelijke veiligheid te verbeteren. Echter, vaak wordt er als vanzelfsprekend van uitgegaan dat vroege preventie tot een win-winsituatie leidt, waarbij zowel betrokken kinderen en gezinnen als ook de maatschappelijke veiligheid erop vooruitgaan. De volgende vijf zorgen laten echter zien dat en waarom de belangen van sommigen in het gedrang kunnen komen, en dat belangenconflicten kunnen ontstaan. Een adequate ethische reflectie op vroege preventie hoort hiermee rekening te houden. Niet ieder kind dat 'opvalt', is meteen een potentiële veelpleger, en het blijft belangrijk om gewoon en onschuldig Pietje Bell-gedrag als zodanig te herkennen (Horstkötter e.a., 2013). Ook een recente bijdrage in het Tijdschrift voor Criminologie laat overtuigend zien dat en waarom het belangrijk is om impulsief en storend gedrag dat mogelijk als ADHD gediagnosticeerd kan worden, niet te zien als voorspeller voor (de aanleg van) crimineel gedrag (De Haan, 2014). 
Ten eerste moet bedacht worden dat kinderen wel de mogelijke lasten van een eventuele screening zullen dragen zonder dat dit hun persoonlijk iets hoeft op te leveren (Juth \& Munthe, 2012). Vooral als het gaat om jonge kinderen die nog geen afwijkend gedrag vertonen, is het onverantwoord wanneer gescreend wordt op afwijkingen of gedragsstoornissen die pas later mogelijk op gaan treden. Hiervan hebben de betrokken kinderen nu geen direct nut, ze kunnen zelfs geschaad worden door mogelijke stigmatisering (Tarini e.a., 2011). Ten tweede bestaat het gevaar dat toekomstige biomedisch geïnformeerde screening en mogelijke toekomstige interventies - niet alleen door leken - als objectief en volstrekt betrouwbaar worden gezien (Skolnick Weisberg e.a., 2008), waardoor de druk deze ook daadwerkelijk toe te passen kan toenemen. Het dienen van de maatschappelijke veiligheid kan zo evident lijken dat het belang van ouders om beslisbevoegdheid over hun kinderen te behouden onder druk kan komen te staan (Kelly, 2000). Een derde valkuil is dat de vaststelling van biomedische verschillen tussen kinderen met en zonder een verhoogd risico op de ontwikkeling van impulsief agressief gedrag ertoe kan leiden dat kinderen met een verhoogd risico als wezenlijk anders en 'gevaarlijk' worden gezien, met alle risico's op labeling, stigmatisering en discriminatie in verschillende domeinen van hun leven van dien (Blank, 2007; Sterzer, 2010). Processen van labeling en stigmatisatie kunnen, ten vierde, een negatief effect hebben op de zelfperceptie en identiteitsontwikkeling van betrokken kinderen. Of, en zo ja, in hoeverre het gevaar van een 'selffulfilling prophecy' bestaat, is ook een belangrijke empirische vraag. Ten slotte kunnen biomedische benaderingen leiden tot een explosieve toename van het gebruik van psychofarmaca (al dan niet in combinatie met psychotherapie), met alle mogelijke negatieve neveneffecten (Singh \& Rose, 2009).

Het moge duidelijk zijn dat de belangen van kinderen en van de maatschappij niet altijd samen hoeven te vallen. Daarom is het onvoldoende om zich uitsluitend te richten op de vraag welke factoren een rol spelen en hoe deze te beïnvloeden zijn. Een primaire vraag is om te bepalen wat in dit verband de belangrijkste doelen zijn (individueel welzijn en autonomie of sociale veiligheid), en wiens belang, dat van het kind of de maatschappij, wanneer en waarom prioriteit heeft.

\section{Vragen over de doelen van vroegpreventie}

Onderzoek naar al bestaande, vooral psychosociaal geïnformeerde, preventie- en interventiepraktijken staat onder het motto van 'wat werkt', dat wil zeggen: of een maatregel goed is, wordt voornamelijk bepaald door zijn effectiviteit (Ince e.a., 2004). Zoals de volgende twee voorbeelden laten zien, is effectiviteit echter wel een noodzakelijke, maar geen voldoende voorwaarde.

Ten eerste, tegenwoordig gelden kinderen die zogenoemd gevoelloos-onemotioneel 'callous-unemotional' gedrag vertonen, als moeilijk behandelbaar. Zij reageren, in tegenstelling tot kinderen zonder dit kenmerk, niet of nauwelijks op bestaande gedragstherapie. De voorgestelde differentiatie kan echter verschillende implicaties hebben. Enerzijds zouden ook voor deze ernstige subgroep passende interventie- en behandelingsstrategieën ontwikkeld kunnen worden. Anderzijds kan deze differentiatie het mogelijk maken vooraf die kinderen te 
identificeren bij wie bestaande therapievormen het meest veelbelovend zijn en de anderen sneller (bij voorbaat) 'af te schrijven'.

Het tweede voorbeeld betreft het onderzoek naar gen-omgevingsinteracties. Men heeft laten zien dat jongens die ernstig mishandeld werden en tevens drager zijn van de korte versie van het monoamine oxidase A (MAOA)-gen vaker antisociaal gedrag laten zien (Caspi e.a., 2002). De implicaties van een dergelijk inzicht in deze genetische kwetsbaarheid hangen echter nauw samen met het doel. Als publieke veiligheid vooropstaat, zou dit kunnen betekenen dat deze kinderen met voorrang worden opgenomen in preventiemaatregelen (Van Goozen \& Fairchild, 2008, 962). De vraag is echter of dit op termijn niet ook tot gevolg kan hebben dat kinderen die mishandeld worden, maar de lange versie van het MAOA-gen dragen, het nakijken hebben. Om dit te voorkomen zou niet publieke veiligheid, maar zouden juist de belangen en bescherming van kinderen, ongeacht hun genetisch profiel, prioriteit moeten genieten.

Meer inzicht in de biomedische werkingsmechanismen kan de vraag naar de juiste prioriteiten niet beantwoorden en levert geen bijdrage aan de oplossing van dergelijke dilemma's. Hiertoe is een normatief kader nodig dat bepaalt waartoe preventie en interventie moeten dienen, wat geldt als 'effectief' en hoe men op een evenwichtige manier met de legitieme belangen van alle betrokkenen rekening kan houden.

Het hiervoor geschetste overzicht laat zien dat het eventuele maatschappelijke nut noch de mogelijke voordelen voor betrokken kinderen en jongeren niet al bij voorbaat opwegen tegen de potentiële risico's. Bovendien zou een focus op maatschappelijke veiligheid en antisociaal gedrag (ASG)-risicotaxatie, zoals deze bijvoorbeeld ook in de toekomstscenario's naar voren komen die de neurocriminoloog Raine in zijn nieuwste boek bespreekt (Raine, 2013), kunnen impliceren dat de status van het 'kind' ondermijnd wordt. Raine schetst - weliswaar met de nodige kanttekeningen - een continuüm tussen screening en preventie van antisociaal gedrag bij kinderen en het voorkómen en behandelen van agressieve criminaliteit bij volwassenen. Het hedendaagse verschil tussen kindheid en volwassenheid kent kinderen een bijzondere status toe. Als volwassenen zijn wij voor hen verantwoordelijk. Deze verantwoordelijkheid wordt bijvoorbeeld vormgegeven in een ook pedagogische, in plaats van een uitsluitend juridische, bejegening niet alleen van kinderen die mogelijk risico lopen, maar ook van kinderen en jeugdigen die al een strafbaar feit hebben gepleegd.

Pro-Justitiabeoordelingen en risicoanalyses van verdachten: kanttekeningen en vragen De kanttekeningen en vragen die geplaatst kunnen worden bij de inzet van neurobiologische of genetische testen in het geval van verdachten van ernstige vergrijpen zijn van een andere orde dan de preventieve screening van kinderen. Immers, er is al een ernstig feit gepleegd. En juist in deze gevallen lijkt het aangewezen om te streven naar een neurobiologisch gefundeerde aanvulling en verbetering van methoden voor forensische beoordeling, vaststelling van toerekenbaarheid, inschatting van de kans op recidive en maatregeladvies voor behandeling. Echter, ook hier is terughoudendheid geboden. In de juridische setting kunnen gedragskundige adviezen verstrekkende gevolgen hebben. Bij verdachten is niet 
altijd zeker of zij de daad gepleegd hebben. En indien de straf uitgezeten is, herkrijgt iemand in principe zijn vrijheid. Een van de basale problemen is dat de kennis van de interacties tussen biologische processen en omgevingsfactoren en hun uitwerkingen op gedrag nog in de kinderschoenen staat. Veel biocriminologisch onderzoek is uitgevoerd op kleine aantallen proefpersonen. Daarmee zijn de generaliseerbaarheid en betrouwbaarheid in het geding. Bovendien geldt altijd dat bij de beoordeling van een individu de resultaten van wetenschappelijk onderzoek op groepsniveau vertaald moeten worden naar het individu. Daarvoor is nog veel valideringsonderzoek nodig. Terwijl op groepsniveau met kansen gerekend kan worden, gaat het bij een individu altijd om een dichotomie: een stoornis is wel of niet aanwezig. Naast een zo adequaat mogelijke diagnose moet vervolgens nog beoordeeld worden of en in welke mate de gevonden afwijking van invloed was op het delict, en of er kans op recidive is. Voor deze beoordelingen zal wetenschappelijke evidentie nooit toereikend zijn. Waar een delinquent bij stress een lage hartslag kan laten zien, heeft dezelfde eigenschap voor een piloot of chirurg positieve gevolgen voor zijn professioneel functioneren in stresssituaties. Hetzelfde geldt voor duiding van beeldvormend materiaal. Een crimineel kan op een scan eenzelfde structurele afwijking laten zien als een ander persoon die geen normoverschrijdend gedrag vertoont. In dit verband is ook gewezen op het gevaar van verwachtingseffecten, hetgeen fout-positieve bevindingen in de hand kan werken (Jelicic \& Merckelbach, 2007). Een neurobiologische 'meting' of scan kan dus nooit op zichzelf staan en zal altijd in combinatie met andere gegevens over een persoon - zoals aanleg, handicaps en psychopathologische kenmerken - en diens ontwikkeling en vooral gedrag geduid moeten worden (De Kogel e.a., 2013; Egger e.a., 2005; Jelicic \& Merckelbach, 2007; Jonker e.a., 2011; Von Borries e.a., 2013). Het opnieuw op de agenda zetten van de biologie impliceert paradoxaal genoeg juist een hernieuwde zoektocht naar omgevingsfactoren.

In ons land biedt tbs de mogelijkheid om door behandeling tot re-integratie te komen. Alles valt of staat met het vertrouwen van burgers, verdachten en daders dat een goede diagnose en behandeling kunnen leiden tot verbetering (WODC, 2011). Gezien het heersende politieke klimaat en de publieke druk, ligt het tbssysteem echter onder vuur. Veel verdachten werken niet mee aan verder onderzoek uit angst na veroordeling door eventuele verlenging van de maatregel voor langere tijd uit de maatschappij verwijderd te worden. Omgekeerd is er veel maatschappelijke verontwaardiging als veroordeelden na terugkeer in de maatschappij opnieuw de fout in gaan, ook al komt dat relatief weinig voor. Het is daarbij de vraag hoe de perceptie zal zijn van de eventuele (verdere) toevoeging van (neuro)biologische elementen aan beoordelingsprocedures en behandeling in de strafrechtsketen. Studies over de invloed van (hypothetische) neurobiologische of genetische testen in de rechtsgang geven een wisselend beeld omtrent de strafmaat (Aspinwall e.a., 2012; Gurley \& Marcus, 2008; Schweitzer \& Saks, 2011). Maar het gevaar is dat de uitkomsten schromelijk worden overschat. In het Nederlandse systeem zou adequate scholing van rechters en duiding door deskundigen kunnen helpen om het huidige gebrek aan evidentie en daarmee vooralsnog 
de relativiteit van de toegevoegde waarde te verduidelijken (Horstkötter e.a., 2014b).

Uit de gezondheidszorg is bekend dat de uitslag van genetische testen bij mensen kan leiden tot meer besef van ziekterisico's en kan motiveren tot interventies. Echter, mensen kunnen ook fatalistisch reageren of de verantwoordelijkheid voor hun gedrag proberen af te schuiven. Maar in tegenstelling tot testen voor afwijkingen waarbij genen een grote rol spelen, is naar de psychologische impact van testen die alleen een genetische kwetsbaarheid aangeven nog weinig onderzoek verricht (Becker e.a., 2011; Pijl e.a., 2009). Niet alleen is verder neuro-ethisch onderzoek noodzakelijk, maar ook is meer onderzoek naar de percepties van verdachten dringend gewenst om te zien of testuitslagen hun zelfbeeld of motivatie beïnvloeden.

De hoop op betere behandelingsmethoden op basis van een adequatere diagnose roept daarnaast ook vragen op over die gevallen waarin subtypering zou uitwijzen dat behandeling juist moeilijk is. Dan is het, net als bij kinderen met een verhoogd risico, de vraag of die gevallen dan al bij voorbaat afgeschreven zouden worden. Mogelijkheden van 'biologische' interventie moeten daarbij niet overschat worden. Bij zedendelinquenten leidt medicatie (chemische castratie) niet in alle gevallen tot ander gedrag. Recent is dan ook een aanpak gepropageerd waarbij in het kader van rehabilitatie sociale netwerken worden gecreëerd om hen van recidive te weerhouden (Höing e.a., 2009; NRC Handelsblad, 2012). Ook dit voorbeeld laat zien dat het belang van de omgeving essentieel is en blijft.

Zelfs in het extreme geval van ernstige gewelddadige criminaliteit bij volwassenen is het dus zaak niet alleen meer kennis te verwerven over eventuele testen die vanuit de neurowetenschappen beschikbaar komen, maar ook helder te krijgen wat de gevolgen zijn voor de positie van de verdachte en het vertrouwen in de rechtsstaat.

\section{Conclusie en aanbevelingen voor verder onderzoek}

Ondanks veelbelovende onderzoeksbevindingen staat het denken over mogelijke toepassingen in de praktijk nog in de kinderschoenen. Verwachtingsmanagement is hier op zijn plaats om teleurstellingen te voorkomen. Want stel dat het technisch mogelijk wordt om bijvoorbeeld het individuele risico op antisociaal gedrag nauwkeuriger te bepalen, dan nog rijst de vraag of, en zo ja, hoe deze kennis op een verantwoorde manier kan worden opgenomen in preventie- en behandeltrajecten. Maar ook hoe deze kennis de rechtsgang en het gedrag van risicogroepen zal beïnvloeden. Hoe waarborgen we een goede balans tussen individuele en collectieve belangen en tussen ieders rechten en plichten? En waar trekken we, met nieuwe en wellicht snel overschatte triomfen van de biomedische wetenschappen in zicht, grenzen?

Natuurlijk, in principe moeten alle inzichten die tot betere praktijken en oordelen kunnen leiden, worden benut. Maar toch is enige terughoudendheid op haar plaats, zeker gezien de wetenschappelijke stand van zaken. Er is daarnaast altijd ook een fundamentele discussie nodig over wat zou moeten gelden als een 'betere 
praktijk'. Daarbij moet rekening worden gehouden met het verschil in de positie van kinderen/jeugdigen zonder gedragsproblemen, van kinderen/jeugdigen met normoverschrijdend gedrag en van volwassen verdachten en veroordeelden van ernstige vergrijpen. Het continuüm dat Raine schetst, bestaat in werkelijkheid uit zeer verschillende praktijken, waar nieuwe technieken en testen op uiteenlopende manieren uitwerken. Niet alleen is meer biomedisch onderzoek nodig, net zo belangrijk is een ethische en maatschappelijke discussie over de mogelijke implicaties van dergelijke ontwikkelingen, en het ontwikkelen van een normatief kader voor een verantwoorde omgang met de nieuwe horizon van mogelijkheden en problemen.

\section{Literatuur}

Aspinwall, L.G., Brown, T.R. \& Tabery, J. (2012). The double-edged sword: does biomechanism increase or decrease judges' sentencing of psychopaths? Science, 337, 846-849.

Beauchaine, T.P., Neuhaus, E., Brenner, S.L. \& Gatzke-Kopp, L. (2008). Ten good reasons to consider biological processes in prevention and intervention research. Development and Psychopathology, 20(3), 745-774.

Becker, F., El, C. van, Ibarreta, D., Zika, E., Hogarth, S., Borry, P., Cornel, M. e.a. (2011). Genetic testing and common disorders in a public health framework: how to assess relevance and possibilities. European Journal of Human Genetics, 19, S6-S44.

Blank, R.H. (2007). Policy implications of the new neuroscience. Cambridge Quarterly of Healthcare Ethics, 16(2), 169-180.

Borries, K. von, Bulten, E. \& Rinne, T. (2013). Van stoornis naar neurocognitie in de behandeling van tbs-patiënten. Justitiële Verkenningen, 39(4), 69-84.

Caspi, A. \& Moffitt, T.E. (2006). Gene-environment interactions in psychiatry: joining forces with neuroscience. Nature Reviews Neuroscience, 7, 583-590.

Caspi, A., McClay, J., Moffitt, T.E., Mill, J., Martin, J., Craig, I.W., Taylor, A., Poulton, R. (2002). Role of genotype in the cycle of violence in maltreated children. Science, 297(5582), 851-853.

Comings, D.E. (2000). The role of genetics in ADHD and conduct disorder - relevance to the treatment of recidivistic antisocial behavior. In: D.H. Fishbein (ed.). The science, treatment, and prevention of antisocial behaviors: application to the criminal justice system. Kingston, NJ: Civic Research Institute, 16-1-16-25.

Egger, J., Tuinier, S. \& Oei, K. (2005). Forensische neurowetenschappen en de verklaring van crimineel gedrag: stand van zaken en aanbevelingen voor de praktijk. Tijdschrift voor Neuropsychologie, 0(0), 11-19.

Engel, G.L. (1977). The need for a new medical model: a challenge for biomedicine. Science, 196(4286), 129-136.

Farrington, D.P. \& Coid, J.W. (eds.). (2003). Early prevention of adult antisocial behaviour. Cambridge, UK: Cambridge University Press.

Farrington, D.P. \& Welsh, B.C. (2007). Saving children from a life of crime. Early risk factors and effective interventions. Oxford, UK: Oxford University Press.

Fishbein, D.H. (2000). The science, treatment, and prevention of antisocial behaviors. Kingston, NJ: Civic Research Institute.

Forzano, F., Borry, P., Cambon-Thomsen, A., Hodgson, S.V., Tibben, A., Vries, P. de, van El, C.G. \& Cornel, M. (2010). Italian appeal court: a genetic predispostion to commit murder? European Journal of Human Genetics, 18(5), 519-521. 
Frick, P.J. \& Petitclerc, A. (2009). The use of callous-unemotional traits to define important subtypes of antisocial and violent youth. In: S. Hodgins, E. Viding \& A. Plodowski (eds.). The neurobiological basis of violence: science and rehabilitation. Oxford, UK: Oxford University Press, 65-83.

Goozen, S.H.M. van \& Fairchild, G. (2008). How can the study of biological processes help designing new interventions for children with severe antisocial behavior? Development and Psychopathology, 20(3), 941-973.

Gurley, J. \& Marcus, D. (2008). The effects of neuroimaging and brain injury on insanity defenses. Behavioral Sciences \& the Law, 26(1), 85-97.

Haan, W. de (2014). Waar zijn toch al die ondeugende kinderen gebleven? Diagnose en behandeling van ADHD ter voorkoming van ernstig en gewelddadig crimineel gedrag. Tijdschrift voor Criminologie, 56(4), 138-147.

Herpertz, S., Wert, U. \& Lukas, W. (2001). Emotion in criminal offenders with psychopathy and bordeline personality. Archives of General Psychiatry, 58(8), 737-745.

Hodgins, S., Viding, E. \& Plodowski, A. (2009). The neurobiological basis of violence. Oxford, UK: Oxford University Press.

Höing, M., Caspers, J. \& Vogelvang, B. (2009). Circles NL. Aanpassingsstudie naar COSA, Cirkels voor Ondersteuning, Samenwerking en Aanspreekbaarheid in Nederland. www.cosanederland.nl/documents/1/09-0300\%20Aanpassingsstudie\%20COSA-def. pdf.

Horstkötter, D., Berghmans, R. \& Wert, G. de (2013). Een potentiële veelpleger of een Pietje Bell? Vroegpreventie van antisociaal gedrag, ethiek en maatschappij. Tijdschrift voor Gezondheidszorg en Ethiek, 23, 52-54.

Horstkötter, D., Berghmans, R. \& Wert, G. de (2014a). Early prevention of antisocial behavior (ASB): a comparative ethical analysis of psychosocial and biomedical approaches. BioSocieties, 9(1), 60-83. DOI: 10.1057/biosoc.2013.36.

Horstkötter, D., Berghmans, R., Slatman, J. \& Wert, G. de (2011). Biologie en psychiatrie: ethische aspecten van de preventie van antisociaal gedrag bij kinderen. Tijdschrift voor Psychiatrie, 53, 739-749.

Horstkötter, D., El, C. van, Kempes, M., Egger, J., Rinne, T., Pieters, T. \& Wert, G. de (2014b). Neuroimaging in the courtroom: normative frameworks and consensual practices. American Journal of Bioethics Neuroscience, 5(2), 37-39.

Ince, D., Beumer, M., Jonkman, H. \& Vergeer, M. (red.). (2004). Veelbelovend en effectief. Overzicht van preventieve projecten en programma's in de domeinen gezin, school, jeugd, wijk. Utrecht: Nederlands Instituut voor Zorg en Welzijn.

Jelicic, M. \& Merckelbach, H. (2007). Hersenscans in de rechtszaal: oppassen geblazen! Nederlands Juristenblad, (44), 2794-2800.

Jonker, C., Matthaei, I., Schouws, S. \& Sikkens, E. (2011). Twee verdachten met hersenletsel en crimineel gedrag. De bijdrage van de neuroloog aan forensisch psychiatrische diagnostiek. Tijdschrift voor Psychiatrie, 53, 181-187.

Juth, N. \& Munthe, C. (2012). The ethics of screening in health care and medicine. Dordrecht: Springer.

Kelly, P. (2000). The dangerousness of youth-at-risk: the possibilities of surveillance and intervention in uncertain times. Journal of Adolescence, 23(4), 463-476.

Kogel, C.H. de (2008). De hersenen in beeld. Den Haag: Boom Juridische uitgevers.

Kogel, K. de, Haselager, P., Jonker, C., Lenoé, F. \& Westgeest, L. (2013). Beperkingen van neurowetenschap en gedragsgenetica in de rechtspraktijk. Nederlands Juristenblad, 88 (45), 3157-3161.

Moffitt, T.E., Caspi, A. \& Rutter, M. (2006). Measured gene-environment interactions in psychopathology. Perspectives on Psychological Science, 1(1), 5-27. 
Nordstrom, B., Gao, Y., Glenn, A., Peskin, M., Rudo-Hutt, A., Schug, R., Raine, A. e.a. (2011). Neurocriminology. Advances in Genetics, 75, 255-283.

NRC Handelsblad. (2012, 10 mei). Amsterdam: behandeling pedo is voorwaarde voor huurhuis.

Nuffield Council on Bioethics. (2002). Genetics and human behaviour: the ethical context. London: Nuffield Council on Bioethics.

Ortiz, J. \& Raine, A. (2004). Heart rate level and antisocial behavior in children and adolescents: a meta-analysis. Journal of the American Academy of Child and Adolescent Psychiatry, 43(2), 154-162.

Pijl M., Timmermans, D.R.M., Claassen, L., Janssens, A.C., Nijpels, G., Dekker, J.M., Marteau, T.M. \& Henneman, L. (2009). Impact of communicating familial risk of diabetes on illness perceptions and self-reported behavioural outcomes: a randomized controlled trial. Diabetes Care, 32, 597-599.

Popma, A., Jansen, L.M.C., Vermeiren, R., Steiner, H., Raine, A., Goozen, S.H.M. van, Doreleijers, T.A.H. e.a. (2006). Hypothalamus pituitary adrenal axis and autonomic activity during stress in delinquent male adolescents and controls. Psychoneuroendocrinology, 31(8), 948-957.

Raine, A. (2013). Het gewelddadige brein. De biologische wortels van crimineel gedrag. Amsterdam: Balans.

Schweitzer, N.J. \& Saks, M.J. (2011). Neuroimage evidence and the insanity defense. Behavioral Sciences and the Law, 29(4), 592-607.

Shirtcliff, E.A., Vitacco, M.J., Graf, A.R., Gostisha, A.J., Merz, J.L. \& Zahn-Waxler, C. (2009). Neurobiology of empathy and callousness: implications for the development of antisocial behavior. Behavioral Sciences and the Law, 27(2), 137-171.

Singh, I. \& Rose, N. (2009). Biomarkers in psychiatry. Nature, 460, 202-207.

Skolnick Weisberg, D., Keil, F.C., Goodstein, J., Rawson, E. \& Gray, J.R. (2008). The seductive allure of neuroscience explanations. Journal of Cognitive Neuroscience, 20(3), 470-477.

Sterzer, P. (2010). Born to be criminal? What to make of early biological risk factors for criminal behavior. American Journal of Psychiatry, 167(1), 1-3.

Sterzer, P. \& Stadler, C. (2009). Neuroimaging of aggressive and violent behaviour in children and adolescents. Frontiers in Behavioral Neuroscience, 3, 1-8. DOI: 10.3389/ neuro.08.035.2009.

Tarini, B.A., Tercyak, K.P. \& Wilfond, B.S. (2011). Commentary. Children and predictive genomic testing: disease prevention, research protection, and our future. Journal of Pediatric Psychology 36(10), 1113-1121. DOI:10.1093/jpepsy/jsr040.

Tremblay, R.E. \& Japel, C. (2003). Prevention during pregnancy, infancy, and the preschool years. In: D.P. Farrington \& J.W. Coid (eds.). Early prevention of adult antisocial behaviour. Cambridge, UK: Cambridge University Press, 205-242.

Viding, E., Fontaine, N.M.G. \& McCrory, E. (2012). Antisocial behaviour in children with and without callous-unemotional traits. Journal of the Royal Society of Medicine, 105(5), 195-200.

Viding, E., Larsson, H. \& Jones, A.P. (2009). Quantitative genetic studies of antisocial behaviour. In: S. Hodgins, E. Viding \& A. Plodowski (eds.). The neurobiological basis of violence: science and rehabilitation. Oxford, UK: Oxford University Press, 251-264.

Viding, E., Jones, A.P., Frick, P.J., Moffitt, T.E. \& Plomin, R. (2008). Heritability of antisocial behaviour at 9: do callous-unemotional traits matter? Developmental Science, 11(1), 17-22.

Vogel, V. de, Vries Robbé, M. de, Spa, E. de \& Wever, E. (2013). Risicotaxatie van geweld in de forensische psychiatrie. MGV, het magazine voor ggz en verslavingszorg, 68(3), 137. 
Wasserman, D. \& Wachbroit, R. (eds.). (2001). Genetics and criminal behavior. Cambridge, UK: Cambridge University Press.

WODC. Ministerie van Veiligheid en Justitie (2006). Special issue 'Biologie en criminologie'. Justitiële Verkenningen, 8.

WODC. Ministerie van Veiligheid en Justitie (2011). Recidive TBS 1974-2008 (factsheet 2011-6). Den Haag. 